\title{
Sustainable and Circular Business Model for Oil \& Gas Offshore Platform Decommissioning
}

\author{
Vincenzo Basile ${ }^{1} \&$ Roberto Vona ${ }^{2}$ \\ ${ }^{1}$ Researcher in Economics and Business Administration, Department of Economics, Management, Institutions - \\ Federico II University of Naples, Italy \\ ${ }^{2}$ Full Professor of Management, Department of Economics, Management, Institutions - Federico II University of \\ Naples, Italy \\ Correspondence: Vincenzo Basile, Federico II University of Naples, Department of Economics, Management, \\ Institutions, Via Cintia, Naples, Italy. E-mail: vincenzo.basile2@unina.it
}

Received: July 18, 2021

doi:10.5539/ijbm.v16n10p1
Accepted: August 4, 2021

Online Published: August 5, 2021

URL: https://doi.org/10.5539/ijbm.v16n10p1

\begin{abstract}
In recent years, the problem of decommissioning and recycling offshore platforms has become an increasingly complex issue for environmental, socio-economic and safety reasons. The decommissioning or sustainable conversion of offshore platforms in the broader context of the circular economy will lead to the acquisition of new technologies and increasingly change values and behaviours towards sustainability in line with new business models. It will also be a complex process as it will require new skills, transformative technologies and the ability to engage all stakeholders. The objective of this study are the Multi-Use Platforms at Sea (MUPS), which represents an interesting solution for the creation of marine areas where different economic and recreational activities can be launched and developed according to the needs of environmental protection (e.g. renewable energies, shellfish farming, decarbonization plants, tourism and recreation).The main research question was the following: "What is the sustainable and circular business model in the literature that can be best used to support the transformation and/or decommissioning of oil platforms?" In addition, "How can the above business model be applied to the case of a platform considering social and environmental impacts?" In the first phase, the research activity focused on a thorough review of the literature on offshore platform decommissioning and sustainable and circular business models. This allowed us to access the Sustainable Circular Business Model Canvas (SCBMC), a conceptual tool that presents a holistic view of the different multi-purpose management options and their social and environmental impacts. This tool could help oil and gas operators (and related industries) address platform mining issues. The methodology adopted was a qualitative analysis. To test the SCBMC, an empirical study was conducted with semi-structured questionnaires given to several stakeholders (including experts, professionals and academics) in the international decommissioning industry. In addition, broader desk research on global offshore case studies was conducted using information sources and secondary sources.
\end{abstract}

In future research, it may be useful to compare the SCBMC with the latest mainstream Circular Business Model (CBM) issues to better assess and quantify the environmental and social impacts of offshore platform decommissioning and to broaden the debate on this topic, considering economic indicators.

Keywords: offshore oil and gas platform decommissioning, business model innovation, circular economy, blue growth, sustainable business model canvas, management

\section{Introduction}

In recent decades, the demand for natural resources and materials (Note 1) has increased at an unprecedented rate. Globally, natural resource consumption has increased from 27 billion tons in 1970 to 89 billion tons in 2017, according to OECD (2019), and is projected to increase further to 167 billion tons in 2060 (Note 2). The environmental consequences of material use are driven by the projected doubling of greenhouse gas emissions, soil, water and air pollution, and harmful impacts on ecosystems. Because of this critical context, there are increasing efforts to move to a more resource-efficient and circular economy. In the pandemic era, where once unthinkable approaches have become the new normal, businesses must continue their efforts towards sustainability. The pandemic COVID -19 is having a profound impact on our economy. Many companies are 
closing, and people are losing their jobs. In the coming years, it will become even more important that our economy follows the principles of environmental and social well-being. The current business model will be doomed to fail if it does not focus on innovation. The established business model has caused natural disasters, drinking water shortages, a growing amount of waste and social inequality.

Therefore, the need and urgency of decommissioning became a major challenge also in terms of technological and social change (Phillips, 2011). The mindset towards sustainability should shift our development models towards low carbon economy (LCE), circular production use and natural resource regeneration. Decommissioning activities for fixed offshore platforms in Adriatic Sea are expected to increase significantly in the coming years (Note 3). The decommissioning industry is driven by maturing oil and gas fields, aging platforms, and fluctuations in oil and gas prices. Moreover, aging oil and gas fields and aging platforms are expected to fuel the growth of the market. Innovation, new technologies, and efficiency could sustain the business challenges posed by continued economic unpredictability, exponential population growth, and increasing demand for the world's natural resources. These forces will be involved in the transition to sustainable and circular business models where the 3 R's (Reduce, Reuse and Recycle) will be the cornerstones for reducing the environmental impact of businesses (Liu et al., 2017).

The usefulness of sustainable business models in the perspective of the oil and gas decommissioning industry has become a critical facet for many platforms, due to the approaching end of useful life and the issue of asset integrity (Basile et al. 2021). To date, only a handful of offshore platforms have been decommissioned around the world, mainly due to a lack of regulatory frameworks and weak decommissioning plans. The lack of decommissioning facilities poses another critical challenge to the management of onshore disposal. As there are several viable options for decommissioning used platforms, a review of these options is needed. In recent years, several studies (Brigitte et al., 2018; Bull et al., 2019) have appeared in the academic literature on the topic of decommissioning offshore platforms (see Table 1) and related aspects such as decarbonisation, waste management (Akinyemi et al., 2020) and hydrogen production from renewable sources (Pflugmann and De Blasio, 2020). In addition, a new paradigm is also emerging, namely that of long-term coexistence between offshore platforms and marine habitats. For example, integrated multitrophic aquaculture (IMTA) provides the by-products, including waste, from one aquatic species as input (fertilizer, food) for another. According to Chopin et al. (2001), farmers combine fed aquaculture (e.g., fish, shrimp) with inorganic (e.g., algae) and organic (e.g., shellfish) aquaculture in this way to create balanced systems for environmental restoration (bio-mitigation), economic stability (improved output, lower costs, product diversification, and risk reduction), and social acceptance (better management practices). In addition, recent studies (Love et al., 2021) note that oil and gas pipelines have also become fish habitat around offshore platforms. This research strongly suggests that keeping the pipelines in place during partial removal is likely to have a positive impact on both fish diversity and abundance, at least for a few years.

Table 1. The main literature contributions on offshore installations decommissioning

\begin{tabular}{|c|c|c|}
\hline References & Focus & Main empirical evidence \\
\hline $\begin{array}{l}\text { Hamzah, } \\
(2003)\end{array}$ & $\begin{array}{l}\text { International rules on } \\
\text { decommissioning of offshore } \\
\text { installations: some observations }\end{array}$ & $\begin{array}{l}\text { "Focusing primarily on the international law and practice of offshore } \\
\text { decommissioning, this paper examines the various global and regional instruments } \\
\text { that attempt to regulate decommissioning. In considering the way forward, } \\
\text { particularly for Third World countries, it concludes that it is necessary for oil } \\
\text { producing countries to enact comprehensive national legislation on the subject." }\end{array}$ \\
\hline $\begin{array}{l}\text { Osmundsen } \\
\text { et al., (2003) }\end{array}$ & $\begin{array}{l}\text { Decommissioning of petroleum } \\
\text { installations - major policy issues. }\end{array}$ & $\begin{array}{l}\text { "Most existing offshore installations are reused or returned to shore for recycling or } \\
\text { disposal. For installations where there is no generic solution, one should proceed on } \\
\text { a case-by-case basis. We provide an overview of international economic and } \\
\text { regulatory issues related to the disposal of petroleum installations and provide } \\
\text { concrete examples through analysis of Norwegian decommissioning policy. The } \\
\text { impact of disposal decisions on the fishing industry, a key stakeholder, is analyzed." }\end{array}$ \\
\hline $\begin{array}{l}\text { Schroeder et } \\
\text { al., (2004) }\end{array}$ & $\begin{array}{l}\text { Ecological and political issues } \\
\text { surrounding decommissioning of } \\
\text { offshore oil facilities in the } \\
\text { Southern California Bight }\end{array}$ & $\begin{array}{l}\text { "Both local marine ecology and political climate play a role in decommissioning } \\
\text { offshore oil production platforms. Compared to the relatively supportive political } \\
\text { climate in the Gulf of Mexico for rigs-to-reefs programs, conflicting social values } \\
\text { among stakeholders at Southern California increase the need for understanding the } \\
\text { ecological impacts of various decommissioning alternatives. Additional scientific } \\
\text { needs in the decommissioning process include further evaluation of platform habitat }\end{array}$ \\
\hline
\end{tabular}


Parente et al., Offshore decommissioning issues: (2006)
Ekins et al., (2006)

Zawawi et al., (2012)

Decommissioning of offshore oi and gas facilities: A comparative assessment of different scenarios.

Decommissioning of the offshore platform: A sustainable framework.

A multi-criteria decision approach Fowler et al., to decommissioning of offshore oil (2014) quality, assessment of regional impacts of decommissioning alternatives on marine populations, and determination of the biological impacts of any residual pollution. The most important management need is a ranking of ecological priorities. Because a significant number of economically important species reside near oil platforms, National Oceanic and Atmospheric Administration Fisheries should consider the impacts of decommissioning alternatives in their overall management plans. Management strategies could include designating reef platforms as marine protected areas"

"Dealing with the decommissioning of petroleum facilities is a relatively new challenge for most producing countries. It is reasonable to assume that industry experience with platform construction is much greater than with platform decommissioning. Even though multiple and diverse efforts are underway to establish international "best practises" standards in this sector, countries still enjoy a rather large degree of discretion, practicing a particular national style in regulating decommissioning activities within the jurisdiction of their state. This paper offers a broad panorama of this discussion, focusing mainly on two controversial aspects. The first one analyses the ex-ante deductibility of decommissioning costs, as they represent an ex-post expense. The second discussion relates to the transfer of decommissioning responsibility in case of transfer of exploration and production rights to new lessees during the project lifetime. Finally, the paper applies concepts commonly used in project finance, as well as structures commonly used in pension fund organisation, to develop insights into these discussions"

"A material and energy flow analysis with corresponding financial flows for different decommissioning scenarios was performed for the different elements of an offshore oil and gas structure. A comparative assessment of the non-financial (particularly environmental) outcomes of the different scenarios was undertaken, with the reference scenario being to leave all structures in place, while other scenarios involved leaving them on the seabed or bringing them ashore for recycling and disposal. The cost of each scenario, when compared to the reference scenario, provides an implicit assessment of the non-financial outcomes (e.g., environmental improvements) should that scenario be adopted by society. The paper concludes that it is not clear that removing the topsides and casing of large steel structures onshore, as currently required by regulations, is environmentally justified; these concrete structures should certainly be left in place; and that leaving foundations, drill cuttings and pipelines in place with subsequent monitoring would also be justified, unless society places a very high value on a clean seabed and trawler access"

"The scope of this work includes decommissioning methods particularly in the Gulf of Mexico where conditions are like Malaysian waters. Evaluations of the methodology as well as sustainability implications are discussed. Common decommissioning methods include one of the following options: complete removal, partial removal, reefing, or reuse. Using the aspects of sustainability as a pillar of the study, a conceptual framework of a viable decommissioning scheme is drawn. It was conceptually determined that redevelopment of the entire structure as a habitable centre has its unique opportunities. Considering the calm conditions in Malaysian waters and the robust construction of the platforms, the restored structures offer the possibility of serving either as Ocean Townships or as futuristic cities, such as a Sea City. This novel idea of decommissioning is presented and discussed further in this paper"

"Thousands of offshore oil and gas facilities around the world will soon be obsolete and will need to be decommissioned within the next decade. Many countries have blanket regulations mandating the decommissioning of obsolete structures, but this option is unlikely to lead to optimal environmental, social and economic outcomes in all situations. We suggest that nations adopt a flexible approach that allows decommissioning options to be selected from the full range of alternatives (including rigs-to-reefs options) on a case-by-case basis. We outline a Multi-criteria Approval ( MA) decision analysis methodology for evaluating and comparing alternative 
Henrion et Multi-attribute decision analysis al., (2015) for decommissioning offshore oil and gas platforms.
Considerations in evaluating

Kruse et al., potential socioeconomic impacts (2015) of offshore platform decommissioning in California. decommissioning options against key selection criteria, including environmental, financial, socioeconomic, and health and safety considerations"

"As part of a larger policy analysis conducted for the State of California, we implemented a decision analysis software tool (PLATFORM) to clarify and evaluate decision strategies against a comprehensive set of objectives. The main options selected for in-depth analysis were complete removal of the platform and partial removal up to 85 feet below the waterline, with the remaining structure converted to an artificial reef to preserve the rich ecosystems supported by the platform's support structure. PLATFORM was instrumental in structuring and conducting key analyses of the impacts of each option (e.g., on cost, fisheries production, air emissions) and greatly improved the team's productivity. Sensitivity analysis showed that disagreement over preferences, particularly the relative importance of strict adherence to leases, had a much greater impact on the preferred option than uncertainty over specific outcomes, such as decommissioning costs. A near-consensus of stakeholders was found in support of partial removal and the rigs-to-reefs programme"

"To help California Natural Resources Agency understand these issues, we assessed the potential socioeconomic impacts of the two most likely options: complete removal and partial removal of the structure to 85 feet below the waterline, leaving the remaining structure in place as an artificial reef, generally defined as a man-made structure with some features that mimic a natural reef. We estimated impacts to commercial fishing, commercial shipping, recreational fishing, non-consumptive boating, and non-consumptive diving SCUBA. Available data supported quantitative estimates for some impacts, semi-quantitative estimates for others, and only qualitative approximations of the direction of impacts for still others. Even qualitative estimates of the direction of impacts and the options likely to be preferred by user groups were useful to the public and decision makers and provided valuable input to the project's integrative decision model. Even qualitative estimates of the likely direction of impacts are subject to uncertainty where interactions between multiple impacts could occur or where user groups include subgroups that would experience the same option differently. In addition, we were unable to quantify impacts to ecosystem value and the larger regional ecosystem due to data gaps on population sizes and dynamics of key species and uncertainty about the platforms' contribution to available hard substrate and associated natural populations off the coast of southern California"

"Thousands of offshore oil and gas facilities worldwide are nearing the end of their operational lives, yet our understanding of the environmental impacts of different decommissioning strategies is incomplete. The focus on a narrow set of criteria in the past has led to a limited assessment of decommissioning effects and restricts decommissioning options in most regions. We provide a comprehensive overview of the environmental effects of decommissioning, analyse case studies, and outline analytical approaches that can improve our understanding of the ecological dynamics of oil and gas structures. We find that ecosystem functions and services increase with structure age and vary with geographic location, so decommissioning decisions must take an ecosystem approach that considers broader habitat and biodiversity values. Aligning decommissioning assessment priorities among regulators and how they are assessed will reduce the likelihood of variable and suboptimal decommissioning decisions. Ultimately, the range of allowable decommissioning options needs to be expanded to optimize the environmental outcomes of decommissioning across the broad range of ecosystems in which platforms are located"

"The consideration of whether to completely remove an oil and gas production platform from the seafloor or leave the submerged mantle as a reef is an upcoming decision for California, as several offshore platforms in both state and federal waters are in the early stages of decommissioning. Laws require a platform to be removed at the end of its production life unless the submerged jacket section continues as a reef
Bull et al, Worldwide oil and gas platf (2019) decommissioning: A review of practices and reefing options 
under state sponsorship. Consideration of the potential fate of fish and invertebrate populations beneath platforms has resulted in the reefing of the jacket section of platforms worldwide rather than its removal at the time of decommissioning. The construction and use of artificial reefs are centuries old and widespread around the world, using a variety of materials. The history leading to the option of reefing platforms began in the mid-20th century with the desire to create generic artificial reefs that would provide fishing opportunities as well as increase fisheries production for the growing U.S. population. The trend to reef platforms at the end of their life followed the oil and gas industry installing thousands of standing platforms in the Gulf of Mexico where they had become popular fishing destinations. (...) Deliberation of reefing decommissioned platforms and many years of scientific study beneath California platforms has culminated in a California State law that now allows consideration of the concept. This paper summarizes the history, practices, published science, and available information involved when considering the reefing option. It is hoped that this material will inform the public, policymakers, and regulators about their upcoming decisions"

"One way of mitigating decommissioning costs is through the sales and reuse of decommissioned items. To achieve this effectively, a reliability assessment of decommissioned items is required. Such an assessment relies on data collected on the Akinyemi et Data integration for offshore various items over the lifecycle of an engineering asset. (...) this research developed al.,(2020) decommissioning a data integration framework that makes use of Semantic Web technologies and ISO al., (2020) management. 15926 - a standard for process plant data integration - for rapid assessment of decommissioned items. The proposed solution helps in determining the reuse potential of decommissioned items, which can save on cost and benefit the environment."

"Here, we introduce the magnitude and variety of these challenges to raise awareness

Developing policies for the end-of-life of energy

Invernizzi et infrastructure: Coming to terms al., (2020) with the challenges of decommissioning.

The Role of Oil and Gas Love et al., Conductors as Fish Habitat at Two (2021) Southern California Offshore Platforms and stimulate debate on the development of reasonable policies for current and future decommissioning projects. Focusing on power plants, the paper provides the foundations for the interdisciplinary thinking required to deliver an integrated decommissioning policy that incorporates circular economy principles to maximize value throughout the lifecycle of energy infrastructures. We conclude by suggesting new research paths that will promote more sustainable management of energy infrastructures at the end of their life."

"Our research strongly suggests that, to the extent possible, retaining conductors during partial removal will likely have a positive influence on both fish diversity and fish abundance, during at least some years."

Note. Our elaboration.

Table 2. The main existing literature on sustainable and circular business models

\begin{tabular}{|c|c|c|}
\hline Authors & Focus & Main empirical evidence \\
\hline $\begin{array}{l}\text { Svensson et al., } \\
\text { (2011) }\end{array}$ & $\begin{array}{l}\text { A corporate effort towards a } \\
\text { sustainable business model }\end{array}$ & $\begin{array}{l}\text { "The company's efforts towards a more sustainable business model can broadly } \\
\text { be divided into factors within the company and factors outside the company. The } \\
\text { case study demonstrates how the carbon footprint on the Earth can be reduced by } \\
\text { focusing and influencing factors outside the company sown production facilities» }\end{array}$ \\
\hline $\begin{array}{l}\text { Boons et al., } \\
(2013)\end{array}$ & $\begin{array}{l}\text { Business models for sustainable } \\
\text { innovation: state-of-the-art and } \\
\text { steps towards a research agenda. }\end{array}$ & $\begin{array}{l}\text { "As the current literature does not offer a general conceptual definition of } \\
\text { sustainable business models, we propose examples of normative requirements that } \\
\text { business models should meet to support sustainable innovations. Finally, we } \\
\text { sketch the outline of a research agenda by formulating several guiding questions» }\end{array}$ \\
\hline $\begin{array}{l}\text { Laukkanen et } \\
\text { al., (2014) }\end{array}$ & $\begin{array}{l}\text { Analyzing barriers to sustainable } \\
\text { business model innovations: An } \\
\text { innovation systems approach }\end{array}$ & $\begin{array}{l}\text { "The central idea of this paper is to examine how the societal transition towards } \\
\text { sustainable business models can be achieved. Through a qualitative Delphi study, } \\
\text { we assess and categorize the key structural and cultural barriers to sustainable } \\
\text { business model innovation. By applying the innovation system approach, we } \\
\text { explain how to overcome existing barriers by strengthening the functions of the } \\
\text { innovation system» }\end{array}$ \\
\hline
\end{tabular}


non-acceptance of circular business models

Joyce et al., The triple-layered business model

et A framework for sustainable al., (2016) circular business model innovation

"For practitioners working on new innovative business models in the realm of the circular economy this paper provides a basic framework for clustering their concepts. By learning about consumer motives leading to non-adoption, this paper also provides support for designing better and more successful business models»

"The Triple-Layered Business Model Canvas is a tool for exploring sustainability-oriented business model innovation. It extends the original business model canvas by adding two layers: an environmental layer based on a lifecycle perspective and a social layer based on a stakeholder perspective. When taken together, the three layers of the business model make more explicit how an organization generates multiple types of value economic, environmental and social»

"Currently, there is a lack of frameworks for supporting business model innovation in companies in the context of a circular economy. The current tools do not offer the needed understanding in the changing business environment and breaking up of current value chains. Furthermore, the impact of the circular economy models and sustainability should be understood through value creation for all stakeholders. The challenge of redesigning business ecosystems is to find the "win-win-win setting" that balances the self-interests of involved actors and sustainability impacts»

«Circular business models based on remanufacturing and reuse promise significant cost savings as well as radical reductions in environmental impact. Variants of such business models have been suggested for decades, and there are notable success stories such as the Xerox product-service offering based on photocopiers that are remanufactured. Still, we are not seeing widespread adoption in the industry. This paper examines causes for reluctance. Drawing on a hypothesis-testing framework of business model innovation, we show that circular business models imply significant challenges to proactive uncertainty reduction for the entrepreneur. Moreover, we show that many product-service system variants that facilitate return flow control in circular business models further aggravate the potential negative effects of failed uncertainty reduction because of increased capital commitments»

«This paper contributes to theory by proposing the concept of value uncaptured and offers a framework for using it as a novel perspective for sustainable business model innovation. Four forms of value uncaptured are used to trigger innovation: value surplus, value absence, value missed, and value destroyed. In the context of sustainability, each value is considered not only from the perspective of economic value but also from the perspectives of environmental and social value»

«The paper examines bodies of literature on business model innovation, sustainability innovation, networks theory, stakeholder theory, and

Business model innovation for

Evans et al., sustainability: Towards a unified (2017)

Baldassarre al., (2017) perspective for creation of sustainable business models

Bridging sustainable business model innovation and user-driven innovation: A process for sustainable value proposition design product-service systems. We develop five propositions that support the creation of SBMs in a unified perspective, which lays a foundation to support organizations in investigating and experimenting with alternative new business models. This article contributes to the emerging field of SBMs, which embed economic, environmental, and social flows of value that are created, delivered, and captured in a value networky

«This research aims at combining principles from both sustainable business model innovation and user-driven innovation to develop more successful, radical, and user-centered sustainable value propositions. Sustainable business model innovation entails developing value propositions that create value for multiple stakeholders at the same time, including customers, shareholders, suppliers, and partners as well as the environment and society. User-driven innovation allows developing solutions that are meaningful for people and profitable for business by involving potential customers, users, and/or other stakeholders in an experimental and iterative design process» 
Lüdeke-Freund et al., (2018)

Bocken et al., (2018)

Guldmann et al., (2019)

Guldmann et al., (2020)

Donner et al (2020)
The sustainable business model pattern taxonomy 45 patterns to support sustainability-oriented business model innovation

Experimenting with a circular business model: Lessons from eight cases

A Design Thinking Framework for Circular Business Model Innovation

Barriers to circular business mode innovation: A multiple-case study

A new circular business model typology for creating value from agro-waste "...we offer a synthesis and consolidation of the available knowledge about SBMs. Following the notion of patterns as problem-solution combinations, we developed, tested, and applied an emulate-method and multi-step approach centered on an expert review process that combines literature review, Delphi survey, and physical card sorting to identify and validate the currently existing SBM patterns. Ten international experts participated in this process. They classified 45 SBM patterns, assigned these patterns to 11 groups along ecological, social, and economic dimensions of sustainability, and evaluated their potential to contribute to value creation. The resulting taxonomy can serve as a basis for more unified and comparable studies of SBMs and for new business model tools that can be used in various disciplines and industries to analyses and consistently develop sustainability-oriented business models»

"Experimentation is an important capability in the transition to a sustainable business. We focused on 'circular economy as a driver for sustainability. The process and role of business model experimentation were analysed. A circular business experimentation framework was developed and applied. We found that 1) experimentation creates internal and external engagement to start business sustainability transitions 2) experiments can help test assumptions in every building block of the business model 3) collaboration with external partners can ease experimentation, and 4) experimentation processes are iterative and require regular learning and sustainability checks»

"Circular business model innovation (CBMI) can support sustainable business transitions, but the process is poorly understood and there is a lack of tools to assist companies in CBMI. This article aims to contribute to closing this gap by developing a framework for CBMI based on a design thinking approach, which can support the CBMI process. A design thinking process typically consists of three innovation spaces, an exploratory, ideation, and a prototyping and testing space. (...) this paper identifies two additional spaces, an introductory and an alignment space, for CBMI. The results derived from the six case companies indicate that the developed framework including its tools and techniques are useful for CBMI»

"The purpose of this article is to provide an overview of the barriers that hinder adoption of circular business models to facilitate circumvention of the barriers and a faster uptake. The research shows that barriers to circular business model innovation are found at all socio-technical levels and, overall, most barriers are encountered by companies at the organizational level, followed by the value chain level, the employee level, and, finally, the market and institutional level»

«Six types of circular business models are identified and discussed: biogas plant, upcycling entrepreneurship, environmental biorefinery, an agricultural cooperative, agropark, and support structure. They differ in their way of value creation and organizational form but strongly depend on partnerships and their capacity to respond to changing external conditions. This study offers the first circular business model typology within the agricultural domain, revealing the interconnectedness of the six different business model types. It provides options for managers in positioning and adapting their business strategies. It highlights the potential of using biomass first for higher added-value products before exploiting it as an energy source. Cascading biomass valorisation at a territorial level will increasingly be important for locally cooperating actors within a circular bioeconomy approach»

Note. Our elaboration.

The scope of this paper includes decommissioning methods, particularly in the Adriatic Sea. Evaluations of the methodology and implications for sustainability are discussed. Standard decommissioning methods include one of the following options: complete removal, partial removal, riffing, or reuse. Using sustainability considerations 
as the pillar of this study, a conceptual framework for a viable decommissioning scheme is drawn. It was theorized that the redevelopment of an entire structure as a habitable node has potential for conservation and public benefit. Given the calm conditions of the Adriatic waters and the characteristics of some of the platforms, the restored structures hold possibilities either as Ocean Townships or as futuristic cities such as a "sea-stead". Climate change and environmental degradation are major threats to the world. To address these challenges, we need a new growth strategy that transforms the current economy and makes resource use efficient and competitive. Moreover, the significant amounts of materials and waste generated during decommissioning could be recycled and reused. Moreover, such recycling and reuse options could provide a cost-effective solution for waste management or the spread of sustainable business models.

Furthermore, with the overarching goal of making Europe carbon neutral by 2050, the European Commission has unveiled a series of policy initiatives to increase the EU's greenhouse gas emissions reduction target from $50 \%$ to $55 \%$ of 1990 levels by 2030 . The plan includes reviewing every existing law for its climate relevance and introducing new laws on the circular economy, including renovation, biodiversity, agriculture and innovation. A Green Deal is designed to promote a. the efficient use of resources through the transition to a clean and circular economy, and $\mathrm{b}$. the restoration of biodiversity and the reduction of pollution. To achieve this goal, action is needed from all sectors of our economy, and actions include: 1. investing in green technologies; 2. supporting industry through business model innovation; 3. introducing cleaner, cheaper and healthier forms of private and public transport; 4. decarbonising the energy industry; 5. ensuring buildings are more energy efficient; 6. working with international partners to improve global environmental standards; and 7. measuring the sustainability and societal impact of an investment in a company or business (Note 4). In view of this new scenario, a Memorandum of Understanding (MoU) on decarbonisation projects in Italy was recently signed between ENI and Saipem. Specifically, the companies intend to identify possible opportunities for cooperation in the capture, use and storage of $\mathrm{CO} 2$ produced by industrial sites on Italian territory. The aim is to drive the decarbonisation process of entire production and supply chains, especially those with the highest energy intensity, through the adoption of strategic plans with immediate actions to combat climate change and achieve $\mathrm{CO} 2$ reduction targets at national and global level. Claudio Descalzi, CEO of ENI, stated the following, "Through this strategic agreement, ENI intends to strengthen its leadership role in the energy transition and accelerate the development of its business model that combines economic and financial sustainability with environmental sustainability. The introduction of technological solutions for decarbonisation, such as carbon capture, use and storage, will be fundamental to the country's energy transition, and ENI can provide unique skills and expertise in the management of production processes and the fight against climate change." Saipem's Chief Executive Officer, Stefano Cao, commented that "The agreement signed with Eni strengthens Saipem's role as a leading player in carbon capture, transport, reuse and storage. We can propose concrete solutions to support the process of reducing carbon dioxide emissions from the energy and production chains of industrial areas in Italy and contribute to the achievement of ambitious national and European targets. These solutions require a high level of specialization, expertise and experience in the sector, which Saipem has developed over the years and is ready to provide in its contribution to Italy's sustainable recovery and in support of the technological and industrial supply chain."

Moreover, seas and oceans are the pillars of the European economy and have great potential for innovation and growth, helping to achieve the objectives of the Europe 2020 strategy for smart, sustainable and inclusive growth (Note 5). Blue Growth is the long-term strategy to support sustainable growth in the maritime industry as a whole and has a major impact on offshore decommissioning. According to European Commission Maritime Affairs, the "blue economy represents approximately 5.4 million jobs and generates nearly $\epsilon 500$ billion in gross value added per year". Multi-Use Platforms at Sea (MUPS) represent an interesting solution for creating marine areas where new businesses can be created and developed, and the blue growth strategy is useful to develop industries that have a high potential for sustainable jobs and growth, such as the following: a. Aquaculture (fisheries websites); b. Coastal tourism; c. Marine biotechnology; d. Marine energy; and e. Seabed mining. Decommissioning options will be influenced by the particular development and external circumstances at the time of decommissioning and may include the following options 1) finding an alternative use for part or all of the structure; 2) recycling part or all of the structure; 3) final disposal of part or all of the structure on land; 4) leaving the structure in place; 5) tipping the structure in place; and 6) disposing of the structure elsewhere in the sea, such as an artificial reef or deep-sea landfill. A multi-assessment approach should be implemented to assess and understand the better decommissioning options for each facility.

This is accomplished by conducting a risk, benefit, and feasibility assessment and reviewing the results of each component to determine the preferred approach for decommissioning the facility. The risk and benefit feasibility 
assessments may include qualitative and quantitative data. In general, no single decommissioning option will satisfy all criteria or stakeholders, especially given the diverse nature and locations of facilities. Decommissioning options should be considered holistically and selected with consideration of reduced risk versus forgone benefits and feasibility to reduce overall risk. Separate comparative assessments may be required for different asset types as outcomes may vary (e.g., platforms, jackets, riser towers, moorings, subsea manifolds, flexible/rigid pipelines, wellheads, etc.). The decommissioning issue requires public consultation to ensure that potentially affected parties have a reasonable opportunity to consider and provide feedback on the potential impacts of conversion activities/proposals relevant to their functions, interests or activities. To be effective, consultation should be considered as a preventative and ongoing mechanism for addressing the impacts and risks associated with decommissioning. Consultation should ensure that any objections or environmental, social or economic concerns are considered and reflected in regulatory submissions (e.g., an environmental plan).

All consultation activities should be conducted under the following principles: Inclusivity (All consultation activities include culture, gender and diverse viewpoints. The views of vulnerable or marginalized groups who may be affected by the activities are sought.), Integrity and Respect (All consultation activities demonstrate openness, honesty and fairness.), Transparency (Transparency is maintained with stakeholders, particularly through the timely provision of information on all plans, developments and changes that may affect them, and notification of all decisions that relate to concerns raised by them.), Accessibility (Information is disclosed in a manner that is easily accessible and understandable to all stakeholders. Technical information is communicated in an accessible format and languages are spoken by relevant stakeholders.), Responsiveness (Identified stakeholder issues and concerns are responded to promptly), and Informed Consultation and Participation (The engagement and consultation process should result in informed participation by affected stakeholders. This requires an in-depth exchange of views and information through organized and iterative consultations that use feedback to shape decision making. The process needs to be documented and capture the views of stakeholders and reflect their different concerns and priorities in terms of impacts, mitigation measures and benefits. The process must also inform stakeholders how their concerns have been addressed).

\section{Conceptual Framework}

While the Business Models (BMs) literature has typically focused on BMs that mainly create, deliver and capture economic value (Osterwalder \& Pigneur, 2010), in the last decade it has focused on BMs that are also linked to social and environmental value (Ritala et al., 2018). The key challenge is to redesign business models in a way that enables companies to generate economic value by unlocking social and environmental value for all potential stakeholders (Schaltegger et al., 2012). Therefore, business model innovations towards sustainability were explained by Bocken et al. (2014) as "innovations that create significantly positive and/or significantly reduced negative impacts for the environment and/or society, through changes in the way the company and its value network create, deliver, and capture value, or change their value proposition" (p.44). In a new scenario, we should expect organizations to more actively address issues such as financial and environmental crises, and to put economic and social inequalities, material resource scarcity, energy needs, and technological development in their strategic focus (Joyce and Paquin, 2016).

To meet the triple bottom line perspective (Note6), sustainable development implies that environmental, social and economic challenges must be addressed primarily by businesses. In other words, the shift of BM towards a triple bottom line aims to achieve economic success through the intelligent design of environmental and social activities. That is, from a perspective that identifies sustainability as a new business opportunity, this approach focuses Business Model Innovation (BMI) on the changes towards sustainable development (Karlusch et al., 2018). BMI enables the integration of sustainability logic into an existing business or a start-up to design an entirely new sustainable business model (Bocken et al., 2014). Thus, according to Schaltegger et al. (2012), there are three initial assumptions for a company going through the sustainable BMI process: 1 . There must be voluntary contributions to solving societal or environmental problems, because a company's initiatives cannot only be a response to regulations or legal constraints related to the industry structure. 2. rather, there must be positive economic value created for the company and stakeholders. Direct or indirect effects may include cost savings, increased sales or competitiveness, improved profitability, customer loyalty or reputation, etc. 3. finally, sustainable business leads to integrated social, environmental and economic effects on each other.

\subsection{Sustainable and Circular Business Model}

Companies should make large investments against sustainability, which is still considered a form of corporate greenwashing (Parguel et al., 2011) and not core to corporate strategies. Several studies and categorizations of Sustainable Business Models (SBMs) have been proposed in the academic literature by both scholars (Wells, 
2013; Boons and Lüdeke-Freund, 2013; Clinton and Whisnant, 2014) and corporate practitioners. Bocken et al. (2014) developed a categorization of sustainable business model archetypes to contribute to the design of a business model innovation for sustainability. There are eight archetypes identified by Bocken et al. (2014), which are classified into higher-level groupings that qualify the main type of Business Model Innovation (BMI): technological, social, and organizational innovations. In the academic literature, the classification picks up the main types of innovations classified in Boons and Lüdeke-Freund (2013). The technological cluster includes archetypes with a dominant technological innovation component that involves redesigning manufacturing processes and products; the social cluster includes archetypes with a dominant social innovation component (e.g., innovations in consumer offerings and changing consumer behavior); and finally, the organizational cluster includes archetypes that have a dominant organizational innovation change component that involves, for example, changing the fiduciary responsibility of the firm. Recently, Ritala et al. (2018) discussed and updated the categorization by expanding it from eight archetypes to nine archetypes that are distributed across environmental, social, and economic categories as the main types of innovations.

The reason for changing the overarching categorization stems from the concept of revisiting the triple bottom line approach. The model proposed by Bocken et al. (2014) is the mainstream classification of different SBMs, but there are other types of SBMs. Those that focus more on social aspects, such as Jenkins et al. (2011); Michelini and Fiorentino (2012) and Dohrmann et al. (2015), are linked by Ritala et al. (2018) and highlight the overall lack of consolidation and some contradictions between existing SBMs and their characteristics. Lüdeke-Freund et al. (2018) go beyond the "archetype" concept and revisit the "pattern" theory developed by Alexander et al. (1977). Lüdeke-Freund et al. (2018) consider an SBM pattern as follows: "A sustainable business model pattern describes an environmental, social, and/or economic problem that arises when a firm seeks to create value, and it describes the core of a solution to that problem that can be applied repeatedly to a variety of pathways, situations, contexts, and domains. An SBM pattern also describes the design principles, value-creating activities, and their arrangements required to create a useful problem-solution combination." (p.148). The aim is to create a classification that not only shows the existing models and how they work, but also clarifies the business and sustainability relationships of each SBM. For example, Luedeke-Freund et al. (2018) identify 45 sustainable business model patterns, which they classify into 11 groups and associate with 10 different forms of value creation (see Figure 1). These 11 groups are associated with a specific form of value creation when the authors use a "sustainability triangle" to categorize sustainability problem-solution combinations.

The sustainability triangle is divided into ten areas that address ten different forms of value creation to which the pattern groups can be assigned. This model of pattern taxonomy is intended to provide a comprehensive synthesis and consolidation of a vast literature, as it is intended to provide an innovation push for modifying or creating new business models with a stronger focus on sustainability issues. In fact, it was developed as a "heuristic model for decision making in business model development projects" and as a design tool that can be combined with business modeling tools, such as the Canvas. The Sustainable Circular Business Model Canvas (SCBMC) proposed in this study builds on the ideas and structure of the Business Model Canvas (Osterwalder and Pigneur, 2010), other tools and studies on the circular economy (Mentink, 2014; Lewandowski, 2016) and sustainability (Daou et al., 2020).

The proposal is to provide a generic model for Business Model Innovation (BMI) to help companies design and reconfigure their business models. The whole business ecosystem is changing, and the circular economy needs systematic innovation; therefore, a multi-level analysis is required. The shift towards sustainability and Circular Business Model Innovation (CBMI) should integrate elements of macro (global trends and drivers), meso (ecosystem and value chain collaboration) and micro (companies, customers and consumers) levels (Valkokari et al., 2014). 


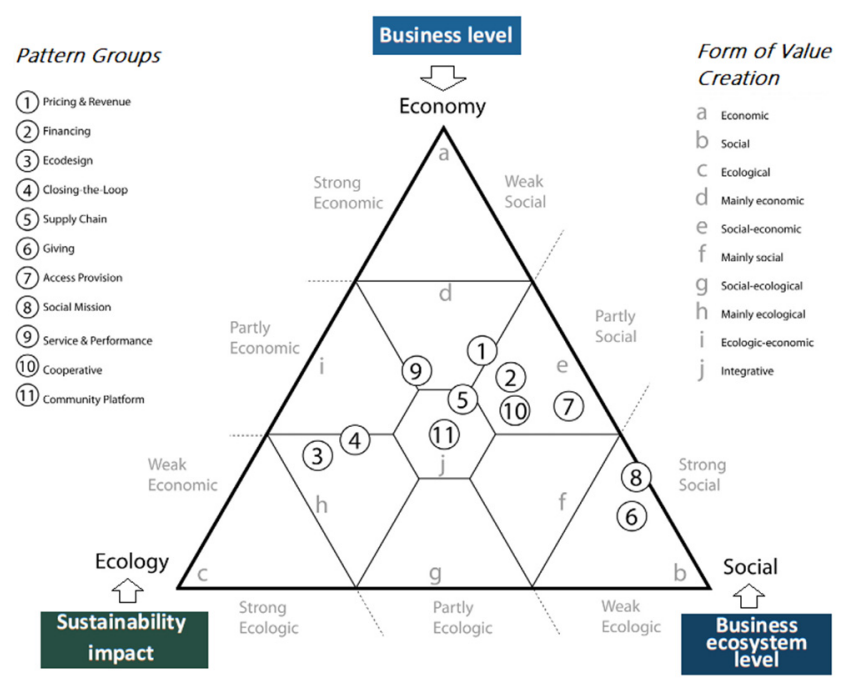

Figure 1. The sustainable business model pattern taxonomy at the group level

Note. Adapted from Lüdeke-Freund et al., 2018.

Trends and drivers involve analysing the business environment and scanning current trends. Business model impacts are divided into sustainability costs and benefits, and a triple bottom line perspective is added to Business Model (BM) development. The canvas includes the idea of continuous iteration with sustainability and circularity assessment of the business model (see Figure 2). These aspects are needed to gain factual data about the sustainability of a BM to optimize the processes and understand the dynamics of the required processes. The sustainability part of this assessment can be done using the developing literature on Life Cycle Assessment (LCA) tools (Klöpffer and Grahl, 2014).

The circular economy perspective focuses on visualizing the model to understand the required actors, relationships, cycle phases, and material and information flows. For example, the three environmental strategies of closing, reducing and slowing down the cycle within the circular economy, as proposed by Kraaijenhagen et al. (2016), can also be assessed. Alternatively, for a more quantitative approach to assessing circularity effects, there is a toolkit for circularity indicators that is currently being built in European Union "The Circularity Indicators Project" of the Ellen MacArthur Foundation (2015).

A successful transition to a Circular Economy (CE) therefore requires systemic changes in the business model with sustainability as a strong foundation. Sustainable business model innovations have become fundamental to corporate competitiveness. Business model innovations are very challenging, especially given that the new circular models are in some cases not more sustainable than the previous ones. This new approach is different from the traditional linear economy that uses a "take, make, dispose of" production model (MacArthur, 2013). CE Scholars (Andersen, 2007; Stahel, 2016; Lacy \& Rutqvist, 2016; Bocken et al., 2016; Lieder \& Rashid, 2016; Kirchherr et al., 2017) suggest that a sustainable world does not mean a reduced quality of life for consumers and can be achieved without loss of revenue or additional costs for businesses. Then Circular Business Models (CBMs) can be as profitable as linear models and allow us to continue enjoying similar products and services. The intermediate step between circular and linear (horizontal) models is represented by the Triple Layer Business Model Canvas (TLBMC).

In contrast to the archetype approach, TLBMC is considered by the authors themselves as an "inside-out" approach to sustainability-oriented business model innovation. It starts from the current elements in the organization to explore the potential changes in the model. In fact, the TLBMC is a recently theorized tool that adds two levels to the original Business Model Canvas (Osterwalder and Pigneur, 2010): an environmental level based on an environmental life cycle analysis and a social level based on a stakeholder management perspective. According to Joyce and Paquin (2016), the TLBMC provides an integrated approach to assist those seeking to understand existing BMs and creatively explore potential sustainability-oriented BMIs. The integration of economic, environmental and social levels supports (vertical coherence) a more robust and holistic view of an organization's business model through its actions and relationships, which can support a more systemic perspective of sustainability-oriented innovation. 


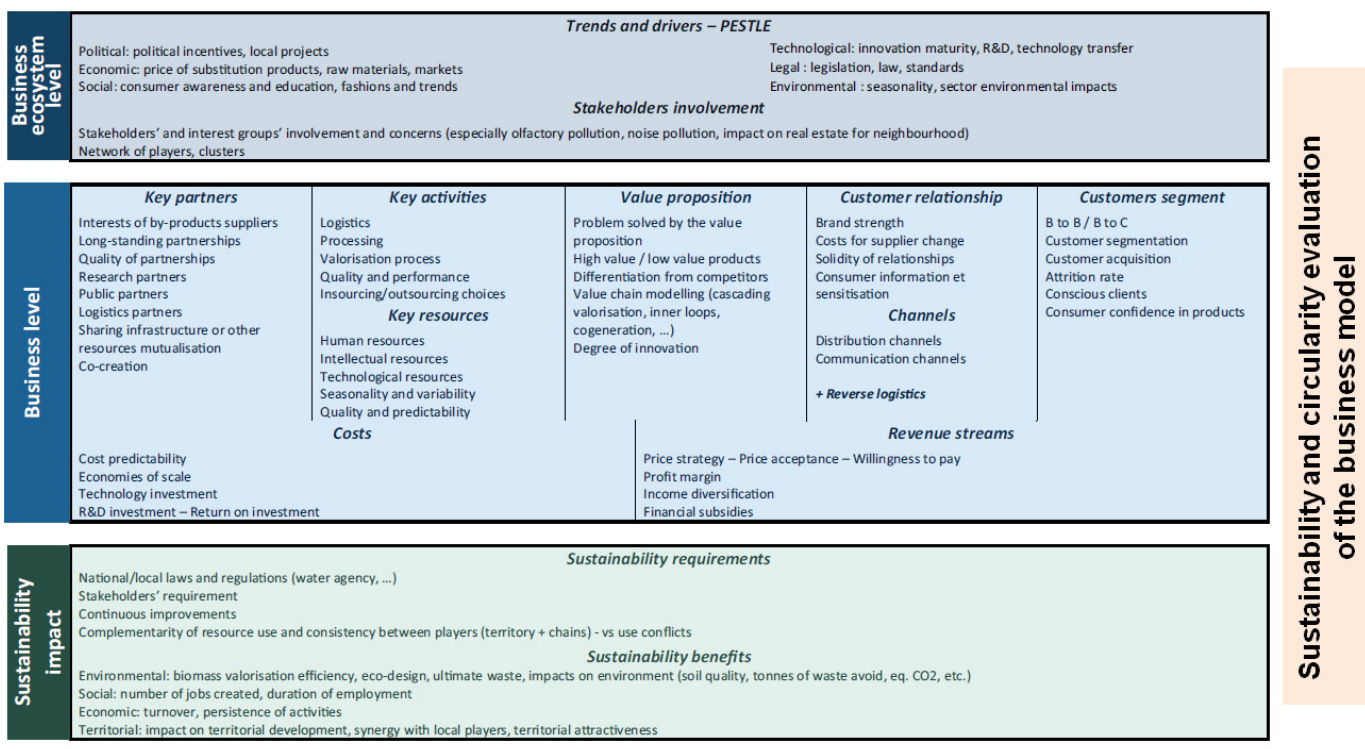

Figure 2. Sustainable circular business model canvas

Note. Adapted from Donner et al., 2020. (Due to space limitations, the questionnaire and the interview protocol will be sent by email on request.)

\section{Methodology}

To select the most relevant management tool for sustainable reconversion of offshore platforms, a literature review was conducted (see Table 2 in the Appendix). First, an analysis of the relevant academic literature (based on the number of citations on Google Scholar, Scopus and the Web of Science and the quality of the academic journals in which the articles were published) on sustainable and circular business models was conducted. The proposed model that emerged from the literature was the Sustainable Circular Business Model Canvas (SCBMC). To test and introduce the SCBMC in the decommissioning industry, an empirical analysis was conducted using semi-structured questionnaires given to several stakeholders (the questionnaire can be found in the Appendix). In the first phase, a study meeting was organized on Chieti-Pescara Chamber (January 24, 2020), where the questionnaires were distributed to stakeholders directly or indirectly involved in the decommissioning industry (Note 7). The questionnaires were used by the group from Federico University II as a tool to test the hypotheses of sustainable transformation of offshore platforms and related business models. As the processing of the questionnaire data continued, both the number and the exploratory contributions of the research were expanded thanks to the contribution of other questionnaires completed by scholars from international universities such as Harvard (Belfer Center for Science and International Affairs) and the University of California.

In addition, scholars working on related issues of decommissioning and environmental sustainability were added to the sample. Respondents to the questionnaire were from North Atlantic, namely from ADRIREEF (Note 8) project partners. After about 6 months, we obtained a dataset consisting of a total of 43 responses. The validation and testing of the SCBMC model by the stakeholders and the questionnaires were enriched by the contribution of a case study on an offshore platform. The structure is in the Adriatic Sea and has features such as the possibility to realize a total conversion of a multipurpose offshore platform (MUPS). A case study approach is best suited in situations where the main research questions are illustrative (Yin, 2014). According to Barnes and Vidgen, (2006) case study is also known as a method where data triangulation is often used to improve research quality. Instead of using sampling methods, case selection maximizes what can be learned in the time available for the study. Later, more information was gathered by analysing posts on social media (Facebook) and web groups related to decommissioning (LinkedIn) (Morente-Molinera, 2018).

This allowed us to explore the issues limited to the Business Model Canvas in relation to the social and environmental impacts that had already emerged in the questionnaires. In addition, broader desk research was conducted on global offshore case studies, using both information sources and secondary sources (Goodwin, 2012). Finally, the methodology was enriched by interviews with key informants (Taylor and Blake, 2015) to better explore the three different perspectives in the SCBMC. 


\section{Discussion}

The main contribution of the SCBMC, applied to offshore platforms (see Figure 3 below), is that it links the logic of how an organization creates, offers and delivers value to its wider stakeholders with the minimisation of environmental and social costs. According to IMO (Note 9) guidelines, any decision not to remove or partially remove should take into account: "the potential impact on the safety of navigation or other uses of the sea; the rate of deterioration of the materials and the potential future impact on the marine environment; the impact on the marine environment; the potential for movement of materials on the seabed; the cost, technical feasibility and safety of personnel; and any new uses for the facility or structure remaining on the seabed or other reasonable justifications". The value propositions for the various stakeholders took the most time in developing the dataset. In particular, understanding end-user needs and value creation for consumers were seen as beneficial and seemed to open new insights for the community. Additionally, the various options for revenue models were discussed at length. Furthermore, the iteration of sustainability and circular economy in the proposed model in conjunction with more detailed cost-benefit analysis (as a decision management tool) will help strengthen the SCBMC. At this early stage, the model can be seen as a good way to communicate a business model to stakeholders, including funders, the public sector and the media. Indeed, the SCBMC is close to the logic of Triple-Layered Business Model Canvas (TLBMC) as a tool for exploring sustainability-oriented business model innovation. According to Joyce and Paquin (2016), the TLMBC adds two layers to the original Business Model Canvas: an environmental layer based on a life cycle perspective and a social layer based on a stakeholder perspective. Taken together, the three-view level of the SCBMC makes it clearer how an organization generates multiple types of economic, environmental, and social value. Therefore, the starting point of the SCBMC is economic sustainability, i.e., the revenue streams that result from the activities triggered by the decommissioning industry.

A solution that will be increasingly important to the company's revenue model in the long term. Carbon capture, storage (CCS) and utilization is a huge opportunity and an important emissions reduction technology that can be applied across the energy industry and provide benefits to society. According to Dr. Emilio Mancuso - President of Verdeacqua (Note 10): "Leaving these structures offshore or dismantling them without effective strategic planning that takes the long view could pose a huge risk to the environment and the community." The model proposed by the respondent is as follows: a) reclaim the platforms, make them usable and safe, and use them as an additional resource to be managed in the long term. Therefore, activities such as integrated multitrophic aquaculture (IMTA) and artificial reefs (which promote underwater tourism) represent sustainable enterprises in this scenario. According to Dr. Andrea Fabris - Director of Italian Fish Farmers Association (Note 11): "The offshore platforms could become Sea Farms, also taking advantage of the market potential arising from the increased demand for fish products. Considering the supply chain, production and the possibility of processing the product. In a hypothesis of reconversion and alternative use of offshore platforms, the development of IMTA technology is strategic because of its environmental and economic impact. IMTA is a production technology capable of reducing pollution while increasing productivity and profits by converting waste streams into new products, allowing for production improvement, supply system diversification, and cost reduction." Furthermore, the SCBMC provides a holistic framework by integrating ecosystem logic, i.e., the "trends and drivers" of the macro-environment with a PESTLE analysis (Capobianco et al., 2021) and stakeholder participation and interaction dynamics. On the other hand, at the lower part of the SCBMC business level are the sustainability impacts. 

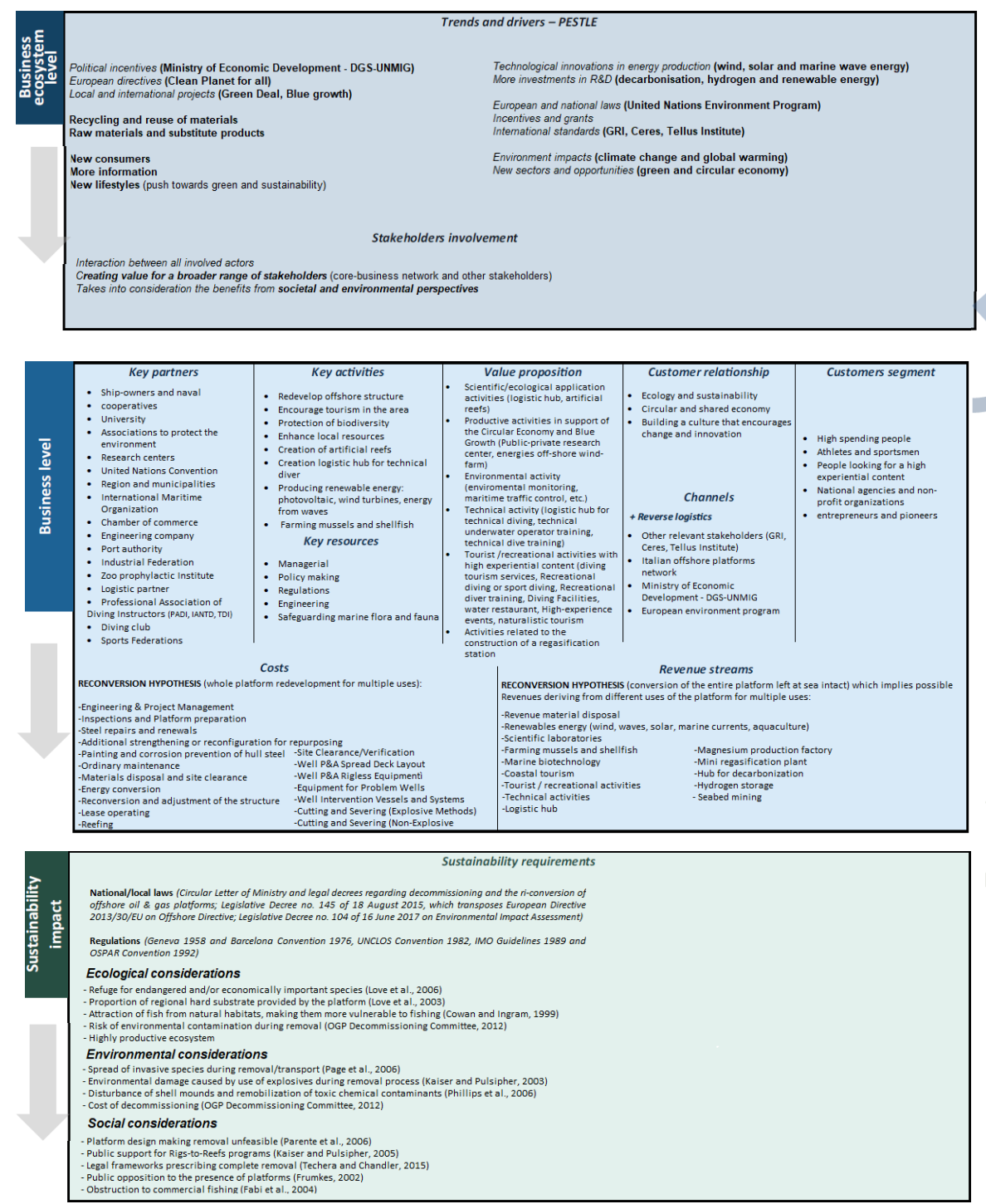

Figure 3. Sustainable circular business model canvas of oil \& gas offshore platforms

Note. Adapted from Antikainen \& Valkokari (2016).

These refer, on the one hand, to the national and international regulations on sustainability requirements and, on the other hand, to the environmental, ecological and social aspects. The GRI standards, for example, harmonize the various laws and seek to create a common language for organizations and companies to report on their sustainability impacts consistently and credibly. This increases global comparability and allows organizations to be transparent and accountable. In addition, the regulations help organizations understand and disclose their impacts in a way that meets the needs of multiple stakeholders. In addition to reporting companies, sustainability requirements are also highly relevant to many other groups such as investors, policymakers, capital markets and civil society. The core of the SCBMC model is the business layer, i.e., the operational logic by which it is possible to create value from the decommissioning and decommissioning of offshore platforms. The nine "building blocks" of the business level were originally proposed by Osterwalder (2005), based on his earlier work on the business model ontology.

\section{Research Limitations}

The main research limitations relate to the qualitative methods used during the first exploratory step, based on in-depth interviews with key informants (Tremblay, 1957). In addition, other limitations relate to the case study analysed (Eisenhardt, 1989; Feagin et al., 2001; Yin, 2013). The aim of the questionnaire was to assess the environmental and socio-economic impacts of different management options related to redundant offshore 
platforms in the Adriatic Sea (i.e., Italian context). Therefore, an analysis should be carried out on several international contexts in order to extend and generalize the findings obtained. The latter could also improve the validity and reliability of further surveys (Ali et al., 2011). According to Guba and Lincoln (1994), internal validity is the degree to which the results can be attributed to the treatment. While external validity is the generalizability of the results and reliability, the extent to which the results can be replicated. Attempts have been made to reduce this limitation through the multi-stakeholder perspective approach in the questionnaire (Tanimoto, 2012). In the next steps, it would be useful to expand the survey with more experts from the oil and gas industry and international academics. In addition, the interviews with key informants should be repeated and expanded (Marshall, 1996), comparing the latest developments of decommissioning strategies and considering the political and environmental choices of governments in line with the goals of the 2030 Agenda (Colglazier, 2015) in conjunction with the blue growth strategy (Eikeset et al., 2018).

\section{Managerial Implications and Direction for Future Research}

A systems perspective on business model innovation takes a comprehensive and holistic view of the entire system, which has multiple layers to consider. Therefore, the proposed SCBMC complements current business model tools (Johnson et al., 2008; Lindgardt et al., 2009; Osterwalder and Pigneur, 2010) by adding the business ecosystem level, sustainability cost and benefit analysis, and iterative cycles of sustainability and circularity assessment considering the end-life of offshore platforms. In addition, business model innovation is based on incremental changes in areas such as key activities, key resources and distribution channels. System innovation, often required in sustainable circular business models, should be considered at multiple levels of the system, which includes cradle-to-cradle (C2C) use of resources (McDonough and Braungart, 2003). Offshore platforms can be assessed under the novel ecosystem approach, using existing decommissioning decision analysis models as a basis. With thousands of platforms scheduled for decommissioning around the world in the coming decades, the novel ecosystem concept provides a mechanism for recognizing the ecological role that offshore platforms play (van Elden et al.,2019). There are several interesting avenues in terms of business model innovation in a circular economy. To innovate in a circular economy, adopting a multidisciplinary perspective plays a key role; therefore, the presented tool combines views from foresight, economics, consumers and sustainability. The first outcome of this research describes the emerging practices for business model innovation based on a circular economy, pointing to several research questions that seem worth further investigation. First, the SCBMC should be tested in several other cases with different companies and industries, ranging from decommissioning to other related industries. Our study does not integrate the financial perspective, which is reinforced by the increasing prevalence of financial products such as green bonds or the Circular Economy Leaders Equity Index, which should measure financial contributions. Second, longitudinal studies could highlight the key stages of business model innovation processes via design or reconfiguration. Third, new methodologies need to be developed, especially for sustainability and circular economy actors, to enable continuous iteration. In the future, sustainable and circular economy approaches (CE) should be further integrated into offshore decommissioning. There is a need to rethink the waste management model, and CE logic offers a way to rethink waste as a resource, integrating conservation and system regeneration, as well as a novel approach to renewable energy (Jensen et al., 2020). This is done with the aim of minimizing resource extraction from the natural environment, maximizing waste prevention measures, and optimizing the use of materials, components, and products throughout their life cycle (Velenturf et al., 2019).

Optimization is guided by values related to improving environmental quality, social well-being, and economic prosperity. These overarching aspirations are often put into practice with 'R-ladders' (i.e., reduce, reuse and recycle). However, these whole life cycle principles have yet to be fully implemented and integrated into the decommissioning industry. In addition, analysis and mapping should be used to identify stakeholder groups that influence a single level of the SCBMC. Early engagement, appropriate consultation strategies, and respectful communication techniques will improve stakeholder interaction and increase the likelihood of meeting the consultation requirements of environmental regulations. Stakeholders may include government agencies, maritime organizations, fishing groups, conservation organizations, scientific organizations, marine users, wildlife societies, wildlife organizations, offshore contractors, tourism operators, local communities, and other groups. For example, the development of offshore IMTA as a sustainable business model requires the identification of environmental and economic risks and benefits of such large-scale systems. Future results of such studies will help determine the practical value of adopting the IMTA approach as a strategy for offshore aquaculture development (Troell et al., 2009). Consultations for new decommissioning activities should consider previous consultations that have been conducted across sectors and by government. Measuring the quality and potential impacts of different scenarios for a transformation project is central to a successful process to be 
implemented successfully. To this end, the introduction of Key Performance Indicators (KPIs) is a necessary step to provide potential quantitative feedback for decommissioning and potential future transformation of the site and to understand the impacts (Williams and Robinson, 2020).

Namely, the technical, social and financial indicators and the environmental impact (which includes the level of pollution and emissions associated with the decommissioning process and the possibility of limiting the exploitation of energy and valuable resources such as water). All these aspects are critical to driving effective transformation, and their combined impact would support a circular intervention. According to Dr. Emilio Mancuso: "Sustainable decommissioning is a great opportunity, but very complex and expensive. Leaving the platforms in the Adriatic Sea without reclamation is a big risk because they can follow the law of entropy and rot on the seabed. If the platforms were well managed and left in the sea and made inert with the environment, there would certainly be an economic, environmental and social benefit."

\section{Acknowledgments}

This research is part of a larger European offshore platform conversion project called PON-PlaCE (Offshore Platform Conversion for Eco-Sustainable Multiples Use). Funding sources: PON Ricerca e Innovazione 20142020, project code, ARS01_00891.

\section{References}

Akinyemi, A. G., Sun, M., \& Gray, A. J. (2020). Data integration for offshore decommissioning waste management. Automation in Construction, 109, 103010. https://doi.org/10.1016/j.autcon.2019.103010

Ali, A. M., \& Yusof, H. (2011). Quality in qualitative studies: The case of validity, reliability and generalizability. Issues in Social and Environmental Accounting, 5(1), 25-64. https://doi.org/10.22164/isea.v5i1.59

Andersen, M. S. (2007). An introductory note on the environmental economics of the circular economy. Sustainability science, 2(1), 133-140. https://doi.org/10.1007/s11625-006-0013-6

Antikainen, M., \& Valkokari, K. (2016). A framework for sustainable circular business model innovation. Technology Innovation Management Review, 6(7). https://doi.org/10.22215/timreview/1000

Barnes, S. J., \& Vidgen, R. T. (2006). Data triangulation and web quality metrics: A case study in e-government. Information \& Management, 43(6), 767-777. https://doi.org/10.1016/j.im.2006.06.001

Basile, V., Capobianco, N., \& Vona, R. (2021). The usefulness of sustainable business models: Analysis from oil and gas industry. Corporate Social Responsibility and Environmental Management. https://doi.org/10.1002/csr.2153

Björkdahl, J., \& Holmén, M. (2013). Business model innovation-the challenges ahead. International Journal of Product Development, 18(3/4), 213-225.

Bocken, N. M., De Pauw, I., Bakker, C., \& Van Der Grinten, B. (2016). Product design and business model strategies for a circular economy. Journal of industrial and production engineering, 33(5), 308-320. https://doi.org/10.1080/21681015.2016.1172124

Bocken, N. M., Schuit, C. S., \& Kraaijenhagen, C. (2018). Experimenting with a circular business model: Lessons from eight cases. Environmental innovation and societal transitions, 28, 79-95. https://doi.org/10.1016/j.eist.2018.02.001

Boons, F., \& Lüdeke-Freund, F. (2013). Business models for sustainable innovation: state-of-the-art and steps towards a research agenda. Journal of Cleaner production, 45, 9-19. https://doi.org/10.1016/j.jclepro.2012.07.007

Bull, A. S., \& Love, M. S. (2019). Worldwide oil and gas platform decommissioning: a review of practices and reefing options. Ocean \& coastal management, $274-306$. https://doi.org/10.1016/j.ocecoaman.2018.10.024

Capobianco, N., Basile, V., Loia, F., \& Vona, R. (2021). Toward a Sustainable Decommissioning of Offshore Platforms in the Oil and Gas Industry: A PESTLE Analysis. Sustainability, 13(11), 6266. https://doi.org/10.3390/su13116266

Casadesus-Masanell, R., \& Ricart, J. E. (2010). Competitiveness: business model reconfiguration for innovation and internationalization. Management Research: Journal of the Iberoamerican Academy of Management. https://doi.org/10.1108/1536-541011066470

Chesbrough, H. (2010). Business model innovation: opportunities and barriers. Long Range Planning, 43(2-3), 
354-363. https://doi.org/10.1016/j.lrp.2009.07.010

Chesbrough, H., \& Rosenbloom, R. S. (2002). The role of the business model in capturing value from innovation: evidence from Xerox Corporation's technology spin-off companies. Industrial and corporate change, 11(3), 529-555. https://doi.org/10.1093/icc/11.3.529

Chopin, T., Buschmann, A. H., Halling, C., Troell, M., Kautsky, N., Neori, A., ... \& Neefus, C. (2001). Integrating seaweeds into marine aquaculture systems: a key toward sustainability. Journal of Phycology, 37(6), 975-986. https://doi.org/10.1046/j.1529-8817.2001.01137.x

Claudy, M. C., Peterson, M., \& O'driscoll, A. (2013). Understanding the attitude-behavior gap for renewable energy systems using behavioral reasoning theory. Journal of Macromarketing, 33(4), 273-287. https://doi.org/10.1177/0276146713481605

Donner, M., Gohier, R., \& de Vries, H. (2020). A new circular business model typology for creating value from $\begin{array}{lllll}\text { agro-waste. Science of the Total Environment, } & 716, & 137065 .\end{array}$ https://doi.org/10.1016/j.scitotenv.2020.137065

Eikeset, A. M., Mazzarella, A. B., Davíðsdóttir, B., Klinger, D. H., Levin, S. A., Rovenskaya, E., \& Stenseth, N. C. (2018). What is blue growth? The semantics of "Sustainable Development" of marine environments. Marine Policy, 87, 177-179. https://doi.org/10.1016/j.marpol.2017.10.019

Ekins, P., Vanner, R., \& Firebrace, J. (2006). Decommissioning of offshore oil and gas facilities: A comparative assessment of different scenarios. Journal of environmental management, 79(4), 420-438. https://doi.org/10.1016/j.jenvman.2005.08.023

Evans, S., Vladimirova, D., Holgado, M., Van Fossen, K., Yang, M., Silva, E. A., \& Barlow, C. Y. (2017). Business model innovation for sustainability: Towards a unified perspective for creation of sustainable business models. Business Strategy and the Environment, 26(5), 597-608. https://doi.org/10.1002/bse.1939

Foss, N. J., \& Saebi, T. (2017). Fifteen years of research on business model innovation: How far have we come, and where should we go? Journal of management, 43(1), 200-227. https://doi.org/10.1177/0149206316675927

Fowler, A. M., Macreadie, P. I., Jones, D. O. B., \& Booth, D. J. (2014). A multi-criteria decision approach to decommissioning of offshore oil and gas infrastructure. Ocean \& Coastal Management, 87, 20-29. https://doi.org/10.1016/j.ocecoaman.2013.10.019

Geissdoerfer, M., Savaget, P., Bocken, N. M., \& Hultink, E. J. (2017). The Circular Economy-A new sustainability paradigm? Journal of cleaner production, 143, 757-768. https://doi.org/10.1016/j.jclepro.2016.12.048

Goodwin, J. (Ed.). (2012). SAGE secondary data analysis. Sage.

Guba, E. G., \& Lincoln, Y. S. (1994). Competing paradigms in qualitative research. Handbook of qualitative research, 2(163-194), 105.

Guldmann, E., \& Huulgaard, R. D. (2020). Barriers to circular business model innovation: A multiple-case study. Journal of Cleaner Production, 243, 118160. https://doi.org/10.1016/j.jclepro.2019.118160

Guldmann, E., Bocken, N. M., \& Brezet, H. (2019). A Design Thinking Framework for Circular Business Model Innovation. Journal of Business Models, 7(1), 39-70.

Hamzah, B. A. (2003). International rules on decommissioning of offshore installations: some observations. Marine Policy, 27(4), 339-348. https://doi.org/10.1016/S0308-597X(03)00040-X

Henrion, M., Bernstein, B., \& Swamy, S. (2015). A multi-attribute decision analysis for decommissioning offshore oil and gas platforms. Integrated environmental assessment and management, 11(4), 594-609. https://doi.org/10.1002/ieam.1693

Invernizzi, D. C., Locatelli, G., Velenturf, A., Love, P. E., Purnell, P., \& Brookes, N. J. (2020). Developing policies for the end-of-life of energy infrastructure: Coming to terms with the challenges of decommissioning. Energy Policy, 144, 111677. https://doi.org/10.1016/j.enpol.2020.111677

Jensen, P. D., Purnell, P., \& Velenturf, A. P. (2020). Highlighting the need to embed circular economy in low carbon infrastructure decommissioning: The case of offshore wind. Sustainable Production and Consumption, 24, 266-280. https://doi.org/10.1016/j.spc.2020.07.012 
Johnson, M. W., Christensen, C. M., \& Kagermann, H. (2008). Reinventing your business model. Harvard business review, 86(12), 57-68.

Joyce, A., \& Paquin, R. L. (2016). The triple layered business model canvas: A tool to design more sustainable business models. Journal of cleaner production, 135, 1474-1486. https://doi.org/10.1016/j.jclepro.2016.06.067

Khanagha, S., Volberda, H., \& Oshri, I. (2014). Business model renewal and ambidexterity: structural alteration and strategy formation process during transition to a $\mathrm{C}$ loud business model. R\&D Management, 44(3), 322-340.

Kirchherr, J., Reike, D., \& Hekkert, M. (2017). Conceptualizing the circular economy: An analysis of 114 definitions. Resources, conservation and recycling, 127, 221-232. https://doi.org/10.1016/j.resconrec.2017.09.005

Klöpffer, W., \& Grahl, B. (2014). Life cycle assessment (LCA): a guide to best practice. John Wiley \& Sons. https://doi.org/10.1002/9783527655625

Kraaijenhagen, C., Van Oppen, C., \& Bocken, N. (2016). Circular business: collaborate and circulate. Circular Collaboration.

Kruse, S. A., Bernstein, B., \& Scholz, A. J. (2015). Considerations in evaluating potential socioeconomic impacts of offshore platform decommissioning in California. Integrated environmental assessment and management, 11(4), 572-583. https://doi.org/10.1002/ieam.1656

Lacy, P., \& Rutqvist, J. (2016). Waste to wealth: The circular economy advantage. Springer.

Laukkanen, M., \& Patala, S. (2014). Analysing barriers to sustainable business model innovations: Innovation systems approach. International Journal of Innovation Management, 18(6), 1440010. https://doi.org/10.1142/S1363919614400106

Lewandowski, M. (2016). Designing the business models for circular economy-Towards the conceptual framework. Sustainability, 8(1), 43. https://doi.org/10.3390/su8010043

Lieder, M., \& Rashid, A. (2016). Towards circular economy implementation: a comprehensive review in context of manufacturing industry. Journal of cleaner production, 115, 36-51.

Lindgardt, Z., Reeves, M., Stalk, G., \& Deimler, M. S. (2009). Business model innovation. When the Game Gets Tough, Change the Game, The Boston Consulting Group, Boston, MA.

Liu, L., Liang, Y., Song, Q., \& Li, J. (2017). A review of waste prevention through 3R under the concept of circular economy in China. Journal of Material Cycles and Waste Management, 19(4), 1314-1323. https://doi.org/10.1007/s10163-017-0606-4

Love, M. S., Clark, S., Mccrea, M., Seeto, K., Jainese, C., Nishimoto, M., ... \& Kui, L. (2021). The Role of Oil and Gas Conductors as Fish Habitat at Two Southern California Offshore Platforms. Bulletin, Southern California Academy of Sciences, 119(3), 68-77. https://doi.org/10.3160/0038-3872-119.3.68

Lüdeke-Freund, F., Carroux, S., Joyce, A., Massa, L., \& Breuer, H. (2018). The sustainable business model pattern taxonomy 45 patterns to support sustainability-oriented business model innovation. Sustainable Production and Consumption, 15, 145-162. https://doi.org/10.1016/j.spc.2018.06.004

Macarthur, E. (2013). Towards the circular economy, economic and business rationale for an accelerated transition. Ellen MacArthur Foundation: Cowes, UK.

Macarthur, E. (2013). Towards the circular economy. Journal of Industrial Ecology, 2, 23-44.

Markides, C. C. (2013). Business model innovation: what can the ambidexterity literature teach us? Academy of Management Perspectives, 27(4), 313-323. https://doi.org/10.5465/amp.2012.0172

Mcdonough, W., \& Braungart, M. (2003). Dalla culla alla culla. Come conciliare tutela dell'ambiente, equità sociale e sviluppo (Vol. 2). Blu Edizioni.

Mentink, B. A. S. (2014). Circular business model innovation: a process framework and a tool for business model innovation in a circular economy.

Morente-Molinera, J. A., Kou, G., Peng, Y., Torres-Albero, C., \& Herrera-Viedma, E. (2018). Analysing discussions in social networks using group decision making methods and sentiment analysis. Information Sciences, 447, 157-168. https://doi.org/10.1016/j.ins.2018.03.020 
Nielsen, K. R. (2020). Handbook of Sustainable Innovation by Frank Boons \& Andrew McMeekin.

OECD. (2019). OECD Environmental Performance Reviews Waste Management and the Circular Economy in Selected OECD Countries Evidence from Environmental Performance Reviews. OECD Publishing.

Osmundsen, P., \& Tveterås, R. (2003). Decommissioning of petroleum installations major policy issues. Energy policy, 31(15), 1579-1588. https://doi.org/10.1016/S0301-4215(02)00224-0

Osterwalder, A., \& Pigneur, Y. (2010). Business model generation: a handbook for visionaries, game changers, and challengers.

Osterwalder, A., Pigneur, Y., \& Tucci, C. L. (2005). Clarifying business models: Origins, present, and future of the concept. Communications of the association for Information Systems, 16(1), 1. https://doi.org/10.17705/1CAIS.01601

Parente, V., Ferreira, D., Dos Santos, E. M., \& Luczynski, E. (2006). Offshore decommissioning issues: Deductibility and transferability. Energy Policy, 34(15), 1992-2001. https://doi.org/10.1016/j.enpol.2005.02.008

Parguel, B., Benoît-Moreau, F., \& Larceneux, F. (2011). How sustainability ratings might deter 'greenwashing': A closer look at ethical corporate communication. Journal of business ethics, 102(1), 15. https://doi.org/10.1007/s10551-011-0901-2

Pflugmann, F., \& De Blasio, N. (2020). Geopolitical and Market Implications of Renewable Hydrogen.

Phillips, F. (2011). The state of technological and social change: Impressions. Technological Forecasting and Social Change, 78(6), 1072-1078. https://doi.org/10.1016/j.techfore.2011.03.020

Pieroni, M. P., Mcaloone, T. C., \& Pigosso, D. C. (2019). Business model innovation for circular economy and sustainability: A review of approaches. Journal of Cleaner Production, 215, 198-216. https://doi.org/10.1016/j.jclepro.2019.01.036

Schroeder, D. M., \& Love, M. S. (2004). Ecological and political issues surrounding decommissioning of offshore oil facilities in the Southern California Bight. Ocean \& Coastal Management, 47(1-2), 21-48. https://doi.org/10.1016/j.ocecoaman.2004.03.002

Stahel, W. R. (2016). The circular economy. Nature, 531(7595), 435-438. https://doi.org/10.1038/531435a

Svensson, G., Wagner, B., \& Høgevold, N. M. (2011). A corporate effort towards a sustainable business model. European Business Review.

Taylor, G. A. J., \& Blake, B. J. (2015). Key informant interviews and focus groups. Data Analysis, 153.

Troell, M., Joyce, A., Chopin, T., Neori, A., Buschmann, A. H., \& Fang, J. G. (2009). Ecological engineering in aquaculture potential for integrated multi-trophic aquaculture (IMTA) in marine offshore systems. Aquaculture, 297(1-4), 1-9. https://doi.org/10.1016/j.aquaculture.2009.09.010

Van Elden, S., Meeuwig, J., Hemmi, J. M., \& Hobbs, R. (2019). Offshore oil and gas platforms as novel ecosystems: a global perspective. Frontiers in Marine Science, 6, 548. https://doi.org/10.3389/fmars.2019.00548

Velenturf, A. P., Archer, S. A., Gomes, H. I., Christgen, B., Lag-Brotons, A. J., \& Purnell, P. (2019). Circular economy and the matter of integrated resources. Science of the Total Environment, 689, 963-969. https://doi.org/10.1016/j.scitotenv.2019.06.449

Williams, S., \& Robinson, J. (2020). Measuring sustainability: An evaluation framework for sustainability transition experiments. Environmental Science \& Policy, 103, 58-66. https://doi.org/10.1016/j.envsci.2019.10.012

Zawawi, N. W. A., Liew, M. S., \& Na, K. L. (2012, DECEMBER). Decommissioning of offshore platform: A sustainable framework. In 2012 IEEE Colloquium on Humanities, Science and Engineering (CHUSER) (pp. 26-31). IEEE. https://doi.org/10.1109/CHUSER.2012.6504275

Zott, C., \& Amit, R. (2010). Business model design: an activity system perspective. Long range planning, 43(2-3), 216-226. https://doi.org/10.1016/j.lrp.2009.07.004 


\section{Notes}

Note 1. Metals (ferrous, non-ferrous) non-metallic minerals (construction minerals, industrial minerals), biomass (wood, food), and fossil energy carriers.

Note 2. The Organisation for Economic Co-operation and Development (OECD), Global Material Resources Outlook to 2060 .

Note 3. An analyst has been monitoring the offshore decommissioning market, and it is poised to grow by $\$ 1.77$ bn during 2020-2024 progressing at a CAGR of 6\% during the forecast period (www.researchandmarkets.com).

Note 4. In addition to Environmental, Social, and Corporate Governance (ESG), there are also specific financial instruments such as green bonds or the Circular Economy Leaders Equity Index.

Note 5. European Commission (www.ec.europa.eu).

Note 6. The "triple bottom line" was initially introduced in 1994 by John Elkington, the founder of a British consultancy called SustainAbility.

Note 7. The questionnaire was submitted to all stakeholders identified thanks to the support of the institutional partners of the PON-Place project.

Note 8. The project partners include the following: the municipality of Ravenna (lead partner), ARPA (Regional Agency for Environmental Protection), CNR (National Research Council), IRBIM, INOGS (National Institute of Oceanography and Experimental Geophysics), the Zadar County Development Agency Zadra Nova, SUNCE (Association for Nature, Environment and Sustainable Development), the University of Zadar, the public Institution RERA SD for the coordination and development of Split-Dalmatia county, the Ruđer Bošković Institute, and the University of Rijeka - Faculty of Maritime Studies.

Note 9. The International Maritime Organization is the competent organization for Article 60 of UNCLOS. In 1989, the IMO adopted Resolution A.672 (16), the "1989 Guidelines and Standards for the Removal of Offshore Installations and Structures on the Continental Shelf and Exclusive Economic Zone" (IMO Guidelines).

Note 10. A non-profit organization that works with the Institute for Studies on the Sea and WWF Travel, and is dedicated to environmental teaching, dissemination, and scientific communication relating to the theme of biodiversity and marine protection.

Note 11. www.api-online.it.

\section{Copyrights}

Copyright for this article is retained by the author(s), with first publication rights granted to the journal.

This is an open-access article distributed under the terms and conditions of the Creative Commons Attribution license (http://creativecommons.org/licenses/by/4.0/). 